\title{
FACTORS ASSOCIATED WITH QUIT ATTEMPTS AND QUITTING AMONG EASTERN HUNGARIAN WOMEN WHO SMOKED AT THE TIME OF PREGNANCY
}

\author{
Kristie L. Foley', Péter Balázs ${ }^{2}$, Andrea Grenczer ${ }^{3}$, Ildikó Rákóczi ${ }^{4}$ \\ ${ }^{1}$ Medical Humanities Program, Davidson College, Davidson, NC, USA \\ ${ }^{2}$ Institute of Public Health, Semmelweis University, Budapest, Hungary \\ ${ }^{3}$ Department of Family Care Methodology, Semmelweis University, Budapest, Hungary \\ ${ }^{4}$ Department of Family Care, University of Debrecen, Nyiregyháza, Hungary
}

\begin{abstract}
SUMMARY
Introduction: The purpose of this research was to assess factors associated with quit attempts and successful smoking cessation among a sample of socioeconomically disadvantaged pregnant women living in Eastern Hungary.

Materials and methods: In-person interviews were conducted among 201 women residing in Eastern Hungary who self-identified as occasional or regular smokers at the time they learned they were pregnant.

Results: $54 \%$ of the women were smokers at the time they learned they were pregnant. Just over half tried to quit, but only $20 \%$ were successful. Factors associated with reduced likelihood of quit attempts included being a regular (vs. occasional) smoker $(\mathrm{OR}=0.36,95 \% \mathrm{Cl} 0.13-1.00)$ and being Roma (vs. non-Roma) (OR=0.32, 95\% Cl 0.14-0.72). Women who completed high school were 71/2 times more likely to quit (OR=7.5, $95 \% \mathrm{Cl} 1.68-33.2$ ) and those who were employed were $7 \frac{1}{2}$ times more likely to quit (OR=7.6, 95\% Cl 1.88-30.35). Regular smokers were $88 \%$ less likely to quit than occasional smokers.

Discussion: Smoking cessation interventions targeting pregnant women are needed in Eastern Hungary. Efforts to integrate smoking cessation into the current excellent pre-natal care and health visitor program will reach most women who are pregnant or who have given birth within the preceding 3 years.
\end{abstract}

Key words: smoking, pregnancy, Roma, maternal and child health, prenatal

Address for correspondence: K. L. Foley, Medical Humanities Program. Box 7135. Davidson College, Davidson, North Carolina. $28035-7135$. USA. E-mail: krfoley@davidson. edu

\section{INTRODUCTION}

A recent study by Tombor et al. (2010) found that 51\% of pregnant women from Budapest and 12 other regions in Hungary were either occasional (22\%) or regular (29\%) smokers (1). The purpose of this research study was to assess factors associated with quit attempts and successful smoking cessation among highrisk, socioeconomically disadvantaged pregnant women living in Eastern Hungary.

According to the 2004 U.S. Surgeon General's Report, women who smoke during pregnancy increase the risk of pre-term birth (PTB), low-birth weight (LBW), stillbirth, and sudden infant death syndrome (2). In addition, maternal active smoking may lead to premature rupture of the membranes, placenta previa, and placental abruption. Among women who are nursing, nicotine is found in breast milk. Furthermore, prenatal exposure to cigarette smoke affects health of the newborn infant and his/her subsequent school performance $(3,4)$.

In 2007, Szabolcs-Szatmár-Bereg County (Eastern Hungary) experienced a high low-birth (11.4\%) and pre-term birth rate $(10.3 \%)$ - the worst in Hungary (5). By 2008 , the $12.3 \%$ of all live births in this county were PTB/LBW. The World Health Organization estimates that $9.6 \%$ of global births were preterm in 2005, with the lowest rates observed in Europe (6.2\%) (6). Although global incidence of low-birth weight is estimated to be higher than pre-term births $(15.5 \%)$, over $95 \%$ of LBW babies are born in developing countries (7). In developed regions, approximately $7 \%$ of babies are born LBW and in Eastern Europe the proportion of LBW is even lower (6.4\%). Szabolcs-SzatmárBereg County clearly exceeds regional and global incidence for pre-term and low-birth weight. High smoking rates coupled with low socioeconomic status of this region may partially explain this disparity.

Szabolcs-Szatmár-Bereg County is one of the least developed regions of Hungary. In 2008, the average county-level GDP per capita was half the national average $(52.4 \%)(8)$. As part of a larger study of correlates of PTB/LBW babies in this region, we found that $29 \%$ of women who gave birth to a PTB/LBW baby in 2008 had previously given birth to a PTB/LBW baby. In addition, a high proportion of Roma families reside in this county. Recent studies show that Roma have disproportionately poorer health than non-Roma resulting from low socioeconomic status (SES), severe social exclusion, and unhealthy behavioural patterns, all of which could influence birth outcomes $(9,10,11)$. Given the extreme poverty, the high proportion of low-birth weight and preterm births, and the high rate of smoking in this region, we identify 
factors associated with quit attempts and successful smoking cessation in order to design and target future interventions to reduce tobacco use among pregnant women in this region. Ultimately, reducing tobacco use among pregnant women should result in a lower incidence of PTB/LBW babies.

\section{MATERIALS AND METHODS}

Sample: This research was approved by human subjects' review boards at Semmelweis University and Davidson College as part of a larger study on building capacity for tobacco research in Hungary. Out of 767 women who gave birth to a pre-term or low-birth weight baby in 2008 and who were living in SzabolcsSzatmár-Bereg County, 382 were reached and consented to participate in an in-person structured interview ( $50 \%$ response rate). At the time of the interview, the infant was at home and was between 3-15 months of age. Because our study was focused on women who smoked at the time they learned that they were pregnant, only these women $(n=206)$ were deemed eligible. Five cases were dropped due to inconsistent and/or missing data on smoking status pre- and post-pregnancy. The final analytical sample consisted of 201 women who were occasional or regular smokers at the time they learned they were pregnant and subsequently gave birth to low-birth weight and/or pre-term infant(s).

Measurement: The outcomes were: attempted to quit smoking during pregnancy $(1=$ yes, $0=$ no) and successfully quit smoking ( $1=0$ cigarettes since learning she was pregnant, $0=\geq 1$ cigarettes). Demographic characteristics include mother's age at pregnancy (age $\geq 18$ vs. $<18$ ), completed high school (12 grades), married/ cohabitating (yes, no), total number of children at home, self-identified as Roma (yes, no), and employed (yes, no). Characteristics of the newborn include gestational age at birth (in weeks) and weight (grams). Economic indicators include household income $<100 \%$ of the poverty level (yes, no) and complete access to water supply mains, sewage, and operational heating (yes, no). Health habits include alcohol use during pregnancy (yes, no, no answer given), daily intake of vegetables (yes, no) and fruits (yes, no) and current breastfeeding (yes, no). External influences includes whether the mother lives with a partner who smokes (yes, no).

Analysis: Descriptive statistics of all variables in the study were conducted. $\chi^{2}$ tests were used to compare differences between those who attempted to quit and those who successfully quit with all covariates. Multivariable logistic regression models were also computed, and results are reported as odds ratios and 95\% confidence intervals. Stata: Release 9 was used for all statistical analyses.

\section{RESULTS}

Characteristics of the Sample: $54 \%$ of the women were smokers at the time they learned they were pregnant. About half tried to quit, but only 1 in 5 was successful (Table 1). The majority was 18 and older and married or living with a partner. The women had on average 3 children (range 1-10). Almost three of four women lived with a partner who smoked. Less than 1 in 5 women had completed high school and $21 \%$ were employed at the time of pregnancy. Half of the sample self-identified as Roma. The vast majority of the women lived in deep poverty and only $37 \%$ of the women lived in dwellings with complete access to water supply mains, sewage, and operational heating. About half consumed vegetables ( $45 \%)$ and fruits ( $48 \%$ ) on a daily basis. Only 3 women reported alcohol use during pregnancy although 15 chose not to answer the questions. At the time of the interview, $80 \%$ were breastfeeding their infants.

Factors Associated with Attempting to Quit: In bivariate analyses, factors associated with attempting to quit included being non-Roma $(74 \%$ vs. $33 \%, \mathrm{p}<0.001)$, completing high school ( $85 \%$ vs. $48 \%, \mathrm{p}<0.001$ ), being employed (79\% vs. $48 \%$, $\mathrm{p}<0.001)$, having complete access to public health amenities ( $75 \%$ vs. $41 \%, p<0.001)$, daily intake of vegetables ( $66 \%$ vs. $44 \%, \mathrm{p}<0.01)$, daily intake of fruits $(69 \%$ vs. $40 \%, \mathrm{p}<0.001)$, and breastfeeding ( $57 \%$ vs. $38 \%, \mathrm{p}<0.05)$. Regular smokers prior to pregnancy were significantly less likely to attempt quitting compared to occasional smokers ( $47 \%$ vs. $78 \%, p=0.001)$. In the multivariable model, being a regular smoker reduced the odds of attempting to quit by $64 \%$ and being Roma reduced the odds of attempting to quit by $68 \%$.

Factors Associated with Quitting: Factors associated with quitting in bivariate analyses included being non-Roma (35\% vs. $6 \%$, $\mathrm{p}<0.001)$, completing high school (67\% vs. $11 \%)$, being employed (55\% vs. $11 \%, \mathrm{p}<0.001$ ), household income $\leq 100 \%$ national poverty level ( $55 \%$ vs. $18 \%, \mathrm{p}<0.01)$, having complete access to public health amenities ( $42 \%$ vs. $7 \%, \mathrm{p}<0.001)$, and daily intake of vegetables $(27 \%$ vs. $15 \%, \mathrm{p}<0.05)$ and fruits $(30 \%$ vs. $12 \%$, $\mathrm{p}<0.001)$. Living with a partner who smokes reduced the chances of quitting $(16 \%$ vs. $36 \%, \mathrm{p}<0.01)$ as did being a regular smoker prior to learning she was pregnant $(13 \%$ vs. $51 \%, p=0.001)$. In the multivariable model, being a regular smoker reduced the odds of quitting by $88 \%$. Women who completed high school and those who were employed were $71 / 2$ times more likely to quit. Having a smoking partner approached statistical significance $(\mathrm{OR}=0.32$, 95\% CI 0.09-1.18, $\mathrm{p}=0.09$ ).

\section{DISCUSSION}

Fifty-four percent of women in this sample were smoking at the time they learned they were pregnant. About half tried to quit, but only $20 \%$ were successful. A review article on a spontaneous quitting among pregnant women has shown that 'spontaneous' quitters are more likely to be better educated, have higher incomes, be married, and be sporadic smokers (11). Spontaneous quitters, who quit without advice or assistance from others, are also more likely to have environments conducive to quitting (e.g., having a non-smoking partner). Thus, our pilot study expands the literature on quit attempts and quitting among pregnant mothers to Eastern Europe and provides additional evidence of the importance of socioeconomic status, educational attainment of the mother, and supportive environments on quitting.

Interventions to maintain abstinence among pregnant women who spontaneously quit has been marginal (10). However, research has demonstrated that advice and assistance from a health care provider coupled with educational material and supportive environments can reduce smoking and improve abstinence $(2,13,14)$. Furthermore, acknowledging the moral and emotional role(s) of the mother may motivate low-income women to stop smoking $(15,16)$. 
Table 1. Factors associated with quit attempts and successful quitting among low-income pregnant women living in Eastern Hungary $(n=201)$

\begin{tabular}{|c|c|c|c|}
\hline & $\begin{array}{l}\text { Characteristics } \\
\text { of the sample } \\
\text { (n=201) } \\
n(\%)\end{array}$ & $\begin{array}{c}\text { Multivariable correlation } \\
\text { with quit attempt } \\
\text { ( } n=184) \\
\text { OR }(95 \% \mathrm{Cl})\end{array}$ & $\begin{array}{c}\text { Multivariable correlation } \\
\text { with quitting } \\
(n=185) \\
\text { OR }(95 \% \mathrm{Cl})\end{array}$ \\
\hline \multicolumn{4}{|l|}{ Outcomes } \\
\hline Tried to quit during pregnancy & $108(54.0)$ & - & - \\
\hline Quit when learned she was pregnant & $41(20.4)$ & - & - \\
\hline \multicolumn{4}{|l|}{ Socio-demographic characteristics of the mother } \\
\hline Completed high school (12 grades) or more & $40(18.3)$ & $1.21(0.31-4.80)$ & $7.48(1.68-33.24)$ \\
\hline Married or cohabitating & $179(89.1)$ & $1.85(0.47-7.21)$ & $10.79(1.00-115.77)$ \\
\hline $\begin{array}{l}\text { Average number of children }(n=198) \\
1-10\end{array}$ & $2.95(1.83)$ & $0.96(0.79-1.18)$ & $1.03(0.73-1.46)$ \\
\hline Self-identified as Roma & $100(49.8)$ & $0.32(0.14-0.72)$ & $0.54(0.13-2.16)$ \\
\hline Employed & $42(21.0)$ & $1.37(0.45-4.18)$ & $7.56(1.88-30.35)$ \\
\hline \multicolumn{4}{|l|}{ Characteristics of the newborn } \\
\hline $\begin{array}{l}\text { Weeks gestation }(n=199) \\
25-41\end{array}$ & $35.0(3.14)$ & $0.98(0.84-1.15)$ & $0.98(0.76-1.25)$ \\
\hline $\begin{array}{l}\text { Weight (grams) }(n=199) \\
480-3500\end{array}$ & $2147.4(501.7)$ & $1.00(0.99-1.00)$ & $0.99(0.99-1.00)$ \\
\hline \multicolumn{4}{|l|}{ Economic indicators } \\
\hline Household income $\leq 100 \%$ of the poverty level $(n=197)$ & $186(94.4)$ & $0.90(0.14-5.63)$ & $0.17(0.02-1.49)$ \\
\hline $\begin{array}{l}\text { Complete access to water supply mains, sewage, and } \\
\text { operational heating }\end{array}$ & $76(36.8)$ & $1.30(0.50-3.34)$ & $0.99(0.25-3.82)$ \\
\hline \multicolumn{4}{|l|}{ Health habits } \\
\hline $\begin{array}{l}\text { Regular (vs. occasional) smoker prior to learning she was } \\
\text { pregnant }\end{array}$ & $164(81.6)$ & $0.36(0.13-1.00)$ & $0.12(0.04-0.39)$ \\
\hline Reported alcohol use during pregnancy & $3(1.5)$ & a & a \\
\hline Daily intake of vegetables & $91(45.3)$ & $2.21(0.92-5.30)$ & $2.07(0.53-8.10)$ \\
\hline Daily intake of fruits & $97(48.3)$ & $1.33(0.56-3.16)$ & $1.04(0.26-4.10)$ \\
\hline Currently breastfeeding infant & $158(79.8)$ & $1.72(0.68-4.31)$ & $1.35(0.34-5.38)$ \\
\hline \multicolumn{4}{|l|}{ External influences } \\
\hline Lives with a partner who smokes $(n=191)$ & $149(72.3)$ & $0.50(0.19-1.29)$ & $0.32(0.09-1.18)$ \\
\hline
\end{tabular}

a Unable to compute the multivariable relationship between alcohol use and quit outcomes due to low variability in responses to this question.

In Hungary, there is an excellent prenatal and postnatal care infrastructure that could play an important supportive role in motivating pregnant women to quit smoking. In our earlier research, the vast majority $(>90 \%)$ of pregnant women had $>5$ prenatal health care visits and all women were seen by a health visitor after delivery. Health visitors meet the women in their homes within 48 hours of leaving the hospital, once a week for the next 6 weeks, once a month up to 12 months, and at least 6 times a year until the end of the third year. The government has a stake in supporting smoking cessation programs for pregnant women given the high cost of health care associated with pre-term and low-birth weight babies. Furthermore, more than twice as many mothers are motivated to quit than are actually successful. Thus, given high health care costs of caring for PTB/LBW babies, the high prevalence of smoking in this population, motivation to quit among mothers, and the existing infrastructure to deliver evidence-based tobacco cessation services, the opportunities to intervene are excellent.

This is the first study to document the correlates between quit attempts and successful quitting among low-income Eastern Hungarian pregnant women who smoke. In addition, the high proportion of Roma women in this study provides further evidence for the socioeconomic challenges experienced among this population and the need for targeted, tailored interventions in this community to reduce tobacco use.

Despite these strengths, several limitations must be acknowledged. First, the findings may not be generalisable to other Eastern European communities. However, the consistency of our findings with those from the United States, United Kingdom, Australia, and Sweden suggests that the correlates of spontaneous quitting are ubiquitous - better education, employment, and supportive environments are important factors for quitting (12). Second, 
the sample size is small and thus may be underpowered to detect significant differences and lead to large standard errors in our multivariable models. Third, the sample included only women who had given birth to $\mathrm{PTB} / \mathrm{LBW}$ babies and requires retrospective reports of smoking behaviour, which may introduce reporting bias and inflates the proportion of smokers in the population. Finally, self-reported tobacco and alcohol use among pregnant women is likely to be under-reported (17).

Despite these limitations, this study was the first to attempt to characterise tobacco use behaviours among a low SES population of pregnant women living in Eastern Hungary. Based on our findings, we strongly support the need for a comprehensive 'quit smoking' intervention among this population with special consideration of the high proportion of Roma women in this community.

\section{Sponsorship}

This research project was supported by the Fogarty International Center, the National Cancer Institute, and the National Institute of Drug Abuse (1 R01 TW007927-01, PI: Kristie Foley, PhD; Co-PI Péter Balázs, MD, $\mathrm{PhD})$.

\section{Declaration of Competing Interests \\ None}

\section{Statement on the Ethical Conduct of Research}

This research was reviewed by the Human Subjects' Institutional Review Board at Davidson College and the Ethical Review Board at Semmelweis University.

\section{REFERENCE}

1. Tombor I, Urbán R, Berkes T, Demetrovics Z. Denial of smokingrelated risk among pregnant smokers. Acta Obstet Gynecol Scand. 2010;89(4):524-30

2. Centers for Disease Control and Prevention. The health consequences of smoking: a report of the Surgeon General [Internet]. Atlanta: Centers for Disease Control and Prevention; 2004 [cited 2010 Jun 20]. Available from: http://www.cdc.gov/tobacco/data_statistics/sgr/2004/complete_report/ index.htm.

3. Kukla L, Hrubá D, Tyrlík M. Influence of prenatal and postnatal exposure to passive smoking on infants' health during the first six months of their life. Cent Eur J Public Health. 2004 Sep;12(3):157-60.
4. Kukla L, Hrubá D, Tyrlík M. Maternal smoking during pregnancy, behavioral problems and school performances of their school-aged children. Cent Eur J Public Health. 2008 Jun;16(2):71-6.

5. Hungarian Central Statistical Office. Demographic yearbook 2007 [Internet]. Budapest: Hungarian Central Statistical Office; 2008 [cited 2010 Jun 17]. Available from: http://portal.ksh.hu/portal/page? pageid $=38,119919 \&$ dad $=$ portal\& schema $=$ PORTAL.

6. Bulletin of the World Health Organization. The worldwide incidence of preterm birth: a systematic review of maternal mortality and morbidity [Internet]. Geneva: WHO; 2010 [updated 2010; cited 2010 Jun 10]. Available from: http://www.who.int/bulletin/volumes/88/1/08-062554/ en/index.html.

7. The United Nations Children's Fund and World Health Organization. Low birthweight: country, regional and global estimates [Internet]. New York: UNICEF; 2004 [cited 2010 Jun 10]. Available from: http://www. unicef.org/publications/files/low birthweight from EY.pdf.

8. Hungarian Central Statistical Office. Regional distribution of gross domestic product (GDP), 2008 [Internet]. Budapest: Hungarian Central Statistical Office; Jun 2010 [cited 2010 Jun 10]. Available from: http:/ portal.ksh.hu/pls/ksh/docs/eng/xftp/idoszaki/egdpter08.pdf.

9. Kolarcik P, Geckova AM, Orosova O, van Dijk JP, Reijneveld SA. To what extent does socioeconomic status explain differences in health between Roma and non-Roma adolescents in Slovakia? Soc Sci Med. 2009 Apr;68(7):1279-84.

10. Kósa Z, Széles G, Kardos L, Kósa K, Németh R, Országh S, et al. A comparative health survey of the inhabitants of Roma settlements in Hungary. Am J Public Health. 2007 May;97(5):853-9.

11. Kósa K, Lénárt B, Ádány R. Health status of the Roma population in Hungary. Orvosi Hetilap. 2002;143:2419-26. (In Hungarian.)

12. Solomon L, Quinn V. Spontaneous quitting: self-initiated smoking cessation in early pregnancy. Nicotine Tob Res. 2004 Apr;6 Suppl 2:S203-16.

13. Centers for Disease Control and Prevention. Best practices for comprehensive tobacco control programs - 2007. Atlanta: Centers for Disease Control and Prevention; 2007.

14. Polanska K, Hanke W, Sobala W, Broszkiewicz M. Smoking cessation intervention during pregnancy in a Polish urban community - what is the target population? Tob Induc Dis. 2002 Jun 15;1(2):121-8.

15. Nichter M, Nichter M, Muramoto M, Adrian S, Goldade K, Tesler L, et al. Smoking among low-income pregnant women: an ethnographic analysis. Health Educ Behav. 2007 Oct;34(5):748-64.

16. Ebert LM, Fahy K. Why do women continue to smoke in pregnancy? Women Birth. 2007 Dec;20(4):161-8.

17. Czeizel AE, Petik D, Puho E. Smoking and alcohol drinking during pregnancy. The reliability of retrospective maternal self-reported information. Cent Eur J Public Health. 2004 Dec;12(4):179-83.

Received July 19, 2010

Accepted in revised form March 7, 2011 